Daniela Mariana CONSTANTIN (POPA)

Universitatea din București, Facultatea de Litere

\title{
LIMBAJUL CORPORATIST \\ ÎNTRE RIGIDITATE, MANIPULARE ȘI GLOBALIZARE
}

Limba română, asemenea celorlalte limbi, se află într-o continuă evoluție, încercând să se adapteze tuturor transformărilor care au loc în societate. Segmentul temporal reprezentat de ultimele trei decenii (de la începutul anilor 90 și până astăzi) este considerat de către lingviști ca o perioadă marcată de modificări substanțiale, cantitative și calitative, la nivelul vocabularului și al frazeologiei, datorate reintegrării societății românești în pulsul lumii actuale, o lume diversă și vulcanică, pendulând între tradiție și inovație, între libertate cvasiabsolută și mecanisme analogice și imitative. Registrul colocvial (cu spontaneitatea şi pitorescul său) a pătruns și s-a dezvoltat (inclusiv în scris) în primul rând ca reacție la clișeele limbii de lemn, iar împrumuturile masive din limbi altădată greu accesibile au asaltat vocabularul și frazeologia românească, fie instituind noi și dinamice domenii, fie orientându-le pe cele deja existente înspre modelele dominante ale lumii actuale. Zonele în care se petrec asemenea fenomene la nivel lingvistic sunt, în general, cele privind activitățile economice "de top" (afaceri, comerț, modă, turism, divertisment etc.), care necesită un management puternic și eficient și care sunt în căutare permanentă de piețe de desfacere. În aceste domenii sunt atrași, așa cum este firesc, atât specialiști, cât și debutanți, în special tineri activi și dornici de cariere atractive și bine remunerate, prin opoziție cu meseriile tradiționale.

In acest sens, tendința unei/unor anumite categorii de vorbitori este aceea de a utiliza cuvinte împrumutate - mărci ale unui tip dorit de apartenență - atât în viața cotidiană, cât și în activitatea profesională. Această atitudine este impusă, pe de o parte, de rațiuni obiective (necesitatea de a se adapta lingvistic la noutățile obiectuale sau abstracte ale lumii actuale, în legătură cu care se vorbește despre imprumuturi necesare), și, pe de altă parte, de dorința de a se integra și de a se menține într-un grup socioprofesional $\mathrm{cu}$ pretenția de a fi considerat în topul unei activități. Suplimentar, folosirea unui limbaj presărat de împrumuturi (mai mult sau mai puțin cunoscute) poate fi motivată de snobism și de dorința de a-l impresiona pe celălalt (așa-numitele imprumuturi de lux), fapt care 
are, de multe ori, efectul invers celui scontat și, în consecință, decredibilizarea promotorului.

Odată cu apariția organizațiilor multinaționale din România (corporații, grupuri de mare anvergură economico-financiară etc.), realitățile caracteristice acestor activități au determinat și la noi apariția unui nou limbaj socioprofesional, așa-numitul limbaj corporatist, caracterizat de predominanța unor cuvinte, frazeologisme și structuri sintactice preponderent de origine anglo-americană.

Lucrarea de față își propune să prezinte, în liniile sale esențiale, limbajul corporatist, accentuând cele trei mari aspecte importante ale acestuia: caracterul rigid, manipulator și globalizant. Subiectul a fost destul de puțin abordat în lingvistica românească, dar îndeajuns de prezent în spațiul public (el a devenit, în ultima vreme, inclusiv motiv de ironie, de obicei amară, fie din partea celor care au părăsit sistemul, fie din partea celor care regretă că nu se află în interiorul lui). Sintagma „limbaj corporatist" nu e (încă) folosită de lingvişti, dar are deja un înțeles destul de clar pentru mulți vorbitori. În esență, ea reprezintă reflectarea la nivelul limbii a relațiilor care se exercită în interiorul companiilor (de regulă, a celor mari și importante) atât între diversele structuri ale acestora (pe orizontală sau pe verticală, interne și/sau externe), cât și în relația lor cu potențialii clienți sau colaboratori, având ca scop maximizarea eficienței activităților promovate.

Sensurile lui corporatist (adjectiv și substantiv) sunt, în general, raportate la corespondentul său abstract corporatism și la corporație: (adj.) „care ține de corporatism, privitor la corporatism"; (s. m. și f.) „adept al corporatismului"; (adj.) "corporativ"[1]. Dubletul corporatism/corporatist are corespondente în principalele limbi de cultură și de civilizație europene (vezi, spre exemplu, fr. corporatisme/corporatiste, it. corporativismo /corporativista, germ. Korporatismus/ korporatistisch) și provine la noi din franceză [2]. La origine, este vorba de lat. neutru corpus (plural corpora) "corp", care, la rândul lui, stă la baza lat. medieval corporare și corporatio, ultimul etimon direct sau indirect al fr. corporation, engl. corporation, it. Corporazione[3], germ. Korporation, rus. korporatija). În TLF (Trésor de la langue française), la corporation se referă la „asociația persoanelor care practică aceeași profesie cu un statut definit, cu o ierarhie, cu un set de monopoluri și privilegii" [4]. În The Concise Oxford Dictionary (1999), engl. corporation este definit ca "a large company or group of companies" (,O companie mare sau un grup de companii"), iar corporatism e definit ca "the control of a state or organization by large interest groups" (,controlul unui stat sau al unei organizații de către grupuri de interese mari"). În același 
TLF (citat mai sus), se precizează că termenul corporation este uneori folosit, după modelul lui corporation din engleza americană, cu sensurile moderne „compagnie, firme, société", alături de sensul analogic „ansamblu de persoane cu activitate și interese comune, permanente sau temporare".

Termenul corporatist e înregistrat și în dicționarele românești cu sensuri mai vechi, specializate, raportate la corporatism (definit mai sus). Adjectivul, mai previzibil, are semnificația „privitor la corporații“: din acest punct de vedere, se vorbește de cultura corporatistă sau de limbajul corporatist (http:// dilemaveche.ro).

Datorită creșterii numărului mare de vorbitori atât in interiorul corporațiilor, cât și în afara lor, limbajul corporatist reușește să iș̦i găsească un statut propriu în sistemul actual al limbii. Adoptarea limbajului corporatist, în interiorul marilor corporații, de către angajații acestora este motivată, în primul rând, din punctul de vedere al eficientizării colaborării și comunicării dintre cele aflate pe teritoriul românesc și cele aflate pe întreg globul.

Limbajul corporatist este un vehicul al ideologiei, care funcționează ca o schemă simplificatoare ce limitează gândirea și exprimarea. Puternic clişeizate, cu un vocabular sărac şi repetitiv, cu scop de manipulare şi distorsiune, formulele se impun şi se propagă, devenind clişee prin frecvența utilizării şi se mențin prin prestigiul sau autoritatea emițătorului. Acest limbaj poate fi considerat, după opinia noastră, un aspect particular al limbii de lemn contemporane. Între cele două forme de comunicare se găsesc atât elemente comune, cât și elemente diferențiatoare. Cele comune se bazează pe relația dintre angajatori/stafful unei companii și angajați: „Posibilitatea dezvoltării unei cariere de succes într-o companie multinațională"; "Acces la cursuri de dezvoltare profesională și programe de pregătire"; „Oportunitatea de a-ți desfășura activitatea într-o companie multinațională și de a dobândi cunoștinte noi”; "Posibilități de dezvoltare profesională prin traininguri interne și externe" etc., (https://ro.indeed.com/Companie-Multinationala), tot așa precum limba de lemn privește relația dintre un aparat de stat represiv, plasat la diverse niveluri de autoritate, și populație: „Nu voi trăda niciodată poporul!”, „Voi face tot ce e bine pentru țară”, „Nu voi abandona; „Să reclădim încrederea românilor!", „Să arătăm că putem să avem în conducere oameni de care să fim mândri că ne reprezintă!”; „Să luptăm pentru propășirea neamului și aducerea României pe cele mai înalte culmi de civilizație multilateral dezvoltată" (https://dictionarexpresii.wordpress.com 2010/04/10/limbade-lemn). 
Cele două modalități de comunicare se bazează pe resurse lingvistice mai ales lexicale, dar și frazeologico-sintactice, materializate atât în discursul oral, cât și în cel scris, ultimul prin intermediul panourilor mobilizatoare, al ghidurilor de bune practici etc. "Binele public", "Comunitatea", "angajamentele europene" (http://www.cdep.ro/pls/steno. / stenostenogramaids=7362\&idm=1\&) sunt cuvinte pe cât de frecvent întâlnite, pe atât de lipsite de conținuturi; "oportunitatea de a munci într-o echipă tânără și entuziastă", ,posibilitatea de a te perfecționa profesional prin training-uri de specialitate", "libertate de acțiune, suport logistic și informațional" (https://www.ejobs.ro), „posibilitatea de dezvoltare a unei cariere într-o firmă dinamică și de succes" (https://globaltech.com.ro/manager-marketing) etc. sunt, de asemenea, sloganuri devenite bunuri comune în operațiunile de promovare sau de recrutare a noilor angajați.

Totodată, cele două modalități de comunicare se diferențiază: în cazul limbajului corporatist actual, engleza deține supremația prin aglomerarea (de multe ori, nejustificată sau abuzivă) de împrumuturi lexicale și frazeologice preluate etimologic, care înlocuiesc corespondente deja existente în limbă, cu minime șanse de coexistență: „target” (în loc de țintă), "business plan" sau "meetting request" (în loc de solicitare/invitație pentru o întâlnire oficială), "job description" (în loc de fişa postului), "business plan" (pentru plan de afaceri), "training-uri" (în loc de cursuri), "job" (în loc de serviciu), "deadline" (în loc de termen limită), "agreement" (în loc de înțelegere) etc., alături de împrumuturi exclusiv semantice ", a fi determinat în a face ceva" (în loc de a fi hotărât). Prin comparație, limba de lemn se remarcă prin diversitatea cuvintelor și a combinațiilor lexicale, fiind mai degrabă redundantă, figurată și permisivă, fără pretenții de exclusivitate:

„va acționa energic, cu hotărâre, cu promptitudine, neabătut, în vederea realizării obiectivelor propuse.../Se vor lua măsurile corespunzătoare pentru realizarea.../S-au constatat deficiențe majore in funcționarea instituțiilor statului.../Reaşezarea prețuilor... (în loc de scumpiri)/Se preconizează schimbări importante în societatea romanescă.../Oamenii legii (în loc de polițişti).../Din punct de vedere politic/social, guvernul a hotărât că.../Reformarea clasei politice este prioritară.../Pe eşichierul politic a mai apărut un partid.../Să gândim pozitiv şi să acționăm constructiv.../Pentru viitorul României, am ales schimbarea.../Victimele accidentului au plecat pe ultimul drum.../Furtuna a lovit cu furie.../Vom propune/Vom realiza/ Vom face/Vom indeplini" etc... (https:// destepti.ro/ce-este-limba-de-lemn).

Un alt aspect care face diferențierea dintre limbajul corporatist și limba de lemn îl constituie încălcarea flagrantă a maximelor conversaționale (definite de Grice), în cazul celei din urmă. Toate mijloacele 
prin care se violează maximele conversaționale devin, privite în ansamblu, tot atâtea modalități prin care relația textului cu realitatea se degradează. Aceasta are un pronunțat și obiectiv caracter formal, emițătorul nu urmărește, de fapt, să informeze receptorul, ci să-i distragă acestuia atenția de la adevăratele probleme, cu alte cuvinte, să-l manipuleze, să-i anihileze astfel puterea de reacție. În exemplul de mai jos, se poate observa o modalitate de încălcare atât a cerințelor maximei cantități, cât și a maximei maniere, care constă în enumerarea redundantă a părților componente ale unui întreg (de obicei, substantive care sunt categorii sociale), dar şi a întregului propriu-zis:

„Încă din primele zile ale acestui an şi ale celui de-al optulea cincinal, puternic însuflețiți de vibrantele îndemnuri adresate națiunii de dumneavoastră (...) comuniștii, ceilalți oameni ai muncii, toți locuitorii județului nostru, sub conducerea organelor și organizațiilor de partid, au acționat cu şi mai mare abnegație şi dăruire revoluționară pentru realizarea ritmică a sarcinilor de plan la toți indicatorii..."(https://www.scribd.com/document/143445436/Limbade-Lemn-in-Perioada-Comunista-Si-Post-comunista).

Limbajul corporatist, spre deosebire de limba de lemn de tip colectivist, are un caracter subiectiv, este asumat conștient de către cei care îl formează și îl promovează: „Sunt manager asistent și particip la un metting", "Trebuie să semnăm asap! E pressure mare” (https:/ / razvanpascu.ro/2011/05/27gandim-si-vorbim-romgleza-amdecat-o-ideea-about-that), cu tendințe spre personalizare marcată, pendulând între pronumele de persoana I și a II-a singular (eu și tu).

Lipsa nuanțării acestui limbaj se datorează mărcilor sale specifice, bazate pe structuri riguroase, care nu oferă o libertate de gândire, pe schematizarea informației, pe brevilocvență, prin folosirea de informații de clișee sau formule fixe, de cuvinte abreviate, îmbinări previzibile, dar mai ales prin abuzul de împrumuturi din limba engleză. Clişeele sunt "obligatoriu optimiste" ca elemente lexicale, parte constitutivă a limbajului corporatist, ("provocare”, "oportunități”, ,spirit de echipă”, "gândire pozitivă", ,team-building", ,focusare", ,prioritare", ,expertiză”, , dedicație totală" (Rodica Zafiu, Dilema veche, Nr. 314 / 18-24 februarie 2010), ajung să fie preluate în mod conştient, $\mathrm{cu}$ intenția de manipulare în mod direct, obținând rezultatul scontat. Impresia de clișeizare se datorează utilizării exagerate a substantivelor sau grupurilor nominale, concomitent $\mathrm{cu}$ reducerea verbelor, ceea ce face ca discursul să se opacizeze şi să devină monoton; este, mai ales, cazul infinitivului lung care, utilizat repetat, face ca fraza să piardă din precizia şi vehemența pe care i le-ar fi asigurat acțiunea verbului: „reorientarea spre Occident, reconcilierea cu Regele”; 
„adoptarea unei atitudini (...) deturnarea voinței"; "aderarea României” (https:/ / www.philologica "oportunități de avansare", „spirit de echipă" (http://www.romlit.ro/index.pl/limbaj_corporatist).

Prin apelul la adjective se aplică, în continuare, aceleaşi etichete pozitive, "temă generoasă şi bine aleasă”, "lider justițiar”, „argumente raționale", „decizia informată, rațională"; "politica serioasă”, „electorat obosit" (https://www.philologica-jassyensia.ro / upload/VI_1_Cretu.pdf); „atitudine pozitivă", "gândire pozitivă" (http://www.romlit.ro/ index.pl/limbaj_corporatist).

Se remarcă folosirea repetată a imperativului impersonal "trebuie", susținut prin adverbul afirmativ „ da” (,Da, Parlamentul trebuie reformat! $\mathrm{Da}$, trebuie luptat împotriva corupției! Da, trebuie o nouă Constituție! Da, trebuie vot uninominal!") şi întărit, în finalul discursului, prin alt imperativ: „Spuneți stop Băsescu!" (https://www.philologicajassyensia.ro/upload/VI_1_Cretu)

Se creează sintagme fixe, cu adevărat stereotipe, mai ales când un anumit substantiv este asociat de cele mai multe ori cu un adjectiv sau cu același, cum ar fi de exemplu: „epoca strălucită”, „nivel înalt", „izbândă deplină", "probleme profund umane", "gândire pozitivă" (http://www.romlit.roindex.pl/limbaj_corporatist). Funcția specifică a adjectivului în limba de lemn este legată de „axiologia imanentă” pe care discursul se obligă să $\quad$ o scoată la suprafață (http:/ / vignette3.wikia.nocookie.net).

Utilizarea construcțiilor pasive şi impersonale: „se cuvine să înțelegem", ",se vorbește", „se impune să facem" etc., oferă un caracter vag mesajului, evitându-se numirea directă a celui ce dădea un ordin sau executa o acțiune.

Un caz aparte în cadrul lexicului ce caracterizează limbajul corporatist, respectiv limba de lemn îl reprezintă abrevierile. Acestea reflectă, în primul rând, denumirea multor partide politice care activează în contextul actual (PSD, PD, PNL, PRM, UDMR, PC etc). Ele sunt însoțite de noi creații lexicale spontane, de genul "pesediştii", "peneliştii", "peremiştii" etc, apărute ca urmare a abrevierii denumirii partidelor şi ale diferitelor instituții şi organizații. Tendința abrevierii cât mai multor cuvinte conduce la vehicularea unor clișee, reproduse mecanic, fără a fi explicate sau descifrate maselor: $\mathrm{COB}$ (Close of Business - final de program), ASAP (as soon as possible - cât de curând posibil), MOM (minutes of meeting - minuta întâlnirii), HR (Human Resources - resurse umane), POS (point of sale - material promoțional folosit la punctul de 
vanzare)".

(https:/ / www.visionconsulting.ro/jargonul-corporatisteficienta-sau-reflex).

Efectul utilizării acestor clișee este de aderare la o opinie (Tatiana Slama-Cazacu, 2000: 4) și de influențare a gândirii receptorului, acesta din urmă văzut și dorit ca o masă fără personalitate și fără putere de discernământ. Aceste formule se impun și își instaurează supremația prin frecvența masivă și repetitivă a utilizării, fiind menținute prin prestigiul sau autoritatea sursei. Este una dintre situațiile în care se manifestă forța persuasivă a cuvântului prin repetare obsesivă, în ciuda unei aparente nonparticipări afective, așadar, prin tehnica „picăturii chinezești” în stare să găurească piatra.

Valorile promovate de corporații au rolul de manipulare indirectă, prin care se construiește o imagine pozitivă a companiei/societăţii, a conviețuirii în interiorul acesteia, precum și a relațiilor dintre șefi și angajați, în care toate problemele se rezolvă cu ajutorul unor formule magice, punând accentul pe concepte "mobilizatoare": dinamică, optimism, tinerețe, autodepășire, concurență etc., dând impresia unei egalități între părți și a iluziei că fiecare angajat îşi poate îndeplini aspirațiile profesionale: "provocare", ,oportunităti", , ,spirit de echipă”, ,gândire pozitivă”, ,teambuilding", ,focusare", "prioritare", „expertiză", "dedicație totală", Dilema veche, Nr. 314 / 18-24 februarie 2010). În acest sens, limba de lemn specifică discursului totalitar stereotip a fost substituită cu un idiom hibrid, romgleza, producând atât reacții de respingere, cât și de o relativă toleranță. În opinia sociologului Alfred Bulai, „o persoană foarte capabilă dintr-o mare companie nu se limitează la nivelul limbajului", justificând faptul că jargonul e conceput pentru a oferi prestigiu angajaților unei companii, pe de-o parte, și pentru a masca incompetența prin cuvinte sofisticate, devenind, de fapt, o altfel de limbă de lemn, pe de altă parte. Unele sunt folosite ",absolut gratuit", așa cum se întâmplă în cazul ședințelor devenite "meeting", ,timesheet"; , "building"; ,job" "description"; ,tool-uri" etc.

Pe același principiu, în cele mai multe companii private din România, cuvintele din engleză sunt folosite pentru a „redesena într-o manieră mai atractivă“ denumiri de posturi prea puțin atractive în limba română. Este cazul secretarelor, de pildă, care au devenit de câțiva ani „manager assitant."(adevarul.ro/life-style/stil-de-viata/limba abe1737c42d5a66381b e63/index html ).

Un alt aspect important al limbajului corporatist ține de caracterul globalizant. Termenul globalizare este creat recent la noi, prin procedeul derivării, pornindu-se de la radicalul glob/global după o serie de modele străine (fr. globalisation, engl. globalization, germ. Globaliesirung) şi care îl 
plasează în sfera vocabularului „internațional” (Cristina Călărașu, 2003:323324).

În lingvistică, ideea de globalizare a apărut ca urmare directă a situației din economie, deci ea ilustrează relația dintre dinamica societății şi necesitățile comunicării (Ibidem, p. 323). Extinderea sectorului privat, solicitarea de către angajatori a unor abilități de comunicare specifice, divizarea domeniului economic în numeroase ramuri de activitate financiar-bancar, management, resurse umane, contabilitate, relaţii internaționale, turism - pătrunderea unei literaturi de specialitate prin intermediul traducerilor, toate aceste aspecte motivează existența în limba română a unui lexic economic care tinde să se încadreze în unul internațional pe cale să se constituie la nivel global, sub dominanța angloamericană. Globalizarea lingvistică este un fenomen, reperabil cu precădere în ultimele decenii, care constă în utilizarea la nivel global a unei limbi comune dominată de influența anglo-americană.

Datorită acestei influențe lingvistice (în special la nivel lexicosemantic, frazeologic și sintactic), limbajul corporatist reprezintă, în relație cu alte limbi și societăți, un exemplu categoric de globalizare („tool-uri"; "overtime/OT"; "badge”; "meeting room"; "lady"; ,target”; "request-uri”; „incentive plans-uri"; „business plan"; "subject”; "teambuilding”; "celengiuri (challenge-uri)”; "prioritizăm”; „tasklist-uri”; „crossborder”; "letter-uri"; ,"template-uri"; „draft-uri"; „follow-up"; „deadline”; „, we keep a low profile"; , we keep a low profile"; "developeri"; "busy"; "pressure”; "helpdesk"; „timeline”; „missed call-uri"; "target-ul”; "teamleader-ul” (http://it-si-altele.blogspot.ro/2011/06/limbajul-de-lemn-corporatist-cemi.html).

Așadar, limbajul corporatist este un fenomen de actualitate, care capătă o relevanță deosebită în noul context socioeconomic pe care îl parcurge societatea, evidențiind noul mod de abordare a problemei relațiilor dintre limbă și societate.

\section{NOTE:}

[1]. Vezi https://dexonline.ro/definitie/corporatist, unde este derivat, riscant şi fără precizări suplimentare, direct din corporatism. Ibidem, vezi şi corporatism s.n. „,sistem economic în care statul limitează, orientează și controlează unitățile constitutive (corporațiile), în scopul eliminării concurenței şi asigurării reușitei economice". Din fr. corporatisme. În DCR3, corporatist s.m. desemnează un „salariat al unei corporații“ (adică al unei mari companii internaționale), așadar individul care se alătură 
organizațiilor de grup/corporațiilor, având obligația de a promova/apăra interesele acestora.

[2]. În franceză, corporatisme („organizație economică și socială de tip corporativ; doctrina promovată de această organizație”) și corporatiste („care este conform modelului propus de corporatism") sunt considerate derivate din radicalul substantivului corporation, cu ajutorul sufixelor -isme și -iste (vezi http:/ / www.cnrtl.fr/definition/corporation).

[3]. În italiană, cuvântul este polisemantic, iar dintre multiplele lui sensuri este de citat cel mai apropiat de semnificația sa actuală, inclusiv românească: „complesso di persone che, svolgendo una comune attività economica, si univano per la tutela degli interessi e per il conseguimento di fini comuni: corporazioni di arti e mestieri; la c. dei mercanti, dei professionisti” ("colectiv de persoane care dezvoltă o activitate economică comunăși care se caracterizează, de asemenea, prin urmărirea prevalentă a unor finalități comune") (vezi http://www.treccani.it/vocabolario/corporazione).

[4]. "Association de personnes exerçant le même métier, ou une branche de ce métier dotée de statuts définis, d'une hiérarchie, d'une police, de rites, de dévotions propres, avec en outre un ensemble de monopoles et de privileges.

\section{REFERINȚE BIBLIOGRAFICE:}

Avram, Mioara, Anglicismele în limba română, Editura Academiei Române, București,1997.

Dilema veche, nr. 314 / 18-24 februarie 2010.

Călăraşu, Cristina, Globalizare lingvistică și anglicizare, în vol. Aspecte ale dinamicii limbii române actuale (coord. Gabriela Pană Dindelegan), vol. II, Editura Universității din București, București, p. 323-336, 2003.

Sala, Marius, Limbi în contact, Editura Enciclopedică, București, 1997.

Stoichițoiu-Ichim, Adriana (2006), Aspecte ale influenței engleze în româna actuală, Editura Universității din București, București, 2006.

Slama, Cazacu, Stratageme comunicaționale şi manipularea, Editura Polirom, Ia;i, 2000.

Zafiu, Rodica, „Limba de lemn”, în Limbaj şi politică, Editura Universității din București, București 2007.

Zafiu, Rodica, „Limbaj corporatist” în România literară, nr. 32, 2008.

https:/ / www.scribd.com/document/143445436/Limba-de-Lemn-in-PerioadaComunista-Si-Postcomunista.

http://www.pruteanu.ro/4doar o vorba/emis034-039.htm. https://ro.wikipedia.org/wiki/Limb\%C4\% 83_de_lemn. adevarul.ro/life-style/stil-de-viata/limba corporatista 66381be63/index.html. https://www.google.ro/search?q.

http:/ /it-si-altele.blogspot.ro/2011/06/limbajul-de-lemn-corporatist-ce-mi.html. https://adevarul.ro/life-style/stil-de-viața/limba-corporatista.

https://www.visionconsulting.ro/jargonul-corporatist-eficienta-sau-reflex. 
https://destepti.ro/ce-este-limba-de-lemn. http://www.diacronia.ro/ro/indexing/details/A20728.

http://www.romlit.ro http://ebooks.unibuc.ro.pdf, p.1-8.);

http://www.treccani.it/enciclopedia/corporatismo_Enciclopedia-del-Novecento

http://www.cnrtl.fr/definition/corporatisme

https://www.duden.de/rechtschreibung/Korporatismus

\title{
The Corporate Language between Rigidity, Manipulation and Globalization
}

\begin{abstract}
Over the last three decades, the current society has witnessed many changes, both politically and economically, and linguistically (especially at the lexico-semantic, phraseological and syntactic level). The "language of wood" specific to the communist regime, totalitarian, is still reflected in another form due to Anglo-American influence. In this sense, the speaker's tendency is to use borrowed words both in daily life and in professional activity. This attitude is imposed, on one hand, on objective reasons (the need to adapt linguistically to the current world, the expanding of innovations in the most diverse fields of human activity, for which the necessary loans are discussed) on the other hand, the desire to integrate and to maintain oneself in a socio-professional group with the pretense of being considered at the top of an activity. Those in a position that favors them can use this language to be motivated by a certain amount of snobbery and the desire to impress the other person by using words or expressions to which she has no access (so-called luxury loans). With the emergence of multinational organizations in Romania (corporations, groups etc.), especially anglicisms began to impress on the Romanian linguistic space, leading to the emergence of a new socio-professional language, namely corporate language, resulting from the mixture of the Romanian language with terms, phraseologies and Anglo-American grammatical constructions. The present paper presents the corporate language, emphasizing its three important aspects: the rigid, manipulative and globalizing character little approached in Romanian linguistics, but enough to be discussed in an extra-linguistic context. The whole presentation is characterized, on one hand, by rigorous structures, without the possibility of nuance, on the other hand, on the manipulator character, in two hypostases (direct and indirect) and on the globalizing character. For our demonstration, the examples were taken from corporatist terms, which we selected from online published articles, from corporative inter-institutional correspondence and from various sites.
\end{abstract}

Key words: wood language, rigidity, manipulation, globalization. 